\title{
Prognosis in women with interval breast cancer: population based observational cohort study
}

\author{
(C) $(1) \Theta$ OPEN ACCESS
}

\author{
Mette Kalager physician and postdoctoral researcher ${ }^{123}$, Rulla M Tamimi assistant professor ${ }^{14}$, \\ Michael Bretthauer professor ${ }^{25}$, Hans-Olov Adami professor ${ }^{16}$
}

${ }^{1}$ Department of Epidemiology, Harvard School of Public Health, Boston, USA; ${ }^{2}$ University of Oslo, Faculty of Medicine, Institute of Health and Society, Oslo, Norway; ${ }^{3}$ Department of Clinical Research, Telemark Hospital, Skien, Norway; ${ }^{4}$ Channing Laboratory, Department of Medicine, Brigham and Women's Hospital, Harvard Medical School, Boston, USA; ${ }^{5}$ Department of Organ Transplantation, Oslo University Hospital, Rikshospitalet, Oslo, Norway; ${ }^{6}$ Department of Medical Epidemiology and Biostatistics, Karolinska Institutet, Stockholm, Sweden

\begin{abstract}
Objective To compare the prognosis in women with interval breast cancer (cancer detected after a normal screening mammogram and before the next scheduled mammogram) with breast cancer detected among women not yet invited to mammography screening (non-screened).
\end{abstract}

Design Population based observational study.

Setting Norwegian breast cancer screening programme, implemented in different counties from 1996 to 2005.

Participants 7116 women with a diagnosis of breast cancer at age 50 to 72 years; 1816 had interval breast cancer and 5300 had a diagnosis of breast cancer but had not yet been invited to screening.

Main outcome measures Characteristics of the breast tumours, and survival of the women using Kaplan Meier curves and multivariable Cox proportional hazard models.

Results Although interval cancers on average were slightly larger than the cancers in women not invited to screening, the histological type or status of axilliary lymph nodes did not differ noticeably between the two groups. Among interval cancers, there were no appreciable trends in size, nodal status, grade, or hormone receptor positivity associated with time since the last normal mammogram as a marker of growth rate. After 10 years of follow-up, the survival rates were $79.1 \%$ (95\% confidence interval $75.4 \%$ to $82.3 \%$ ) among women with interval cancers and $76.8 \%$ (75.3\% to $78.2 \%$ ) among women in the non-screened cancer group (hazard ratio $0.98,95 \%$ confidence interval 0.84 to $1.15 ; P=0.53$ ). Analyses stratified by time since last normal mammogram, age at diagnosis, or screening round showed similar results.

Conclusion The prognosis of women with interval breast cancers was the same as that of women with breast cancers diagnosed without mammography screening.

\section{Introduction}

When mammography screening programmes are fully implemented, interval cancers comprise a substantial proportion of incident breast cancers. Interval cancers may have been overlooked at the last mammography examination or become apparent because they grew so rapidly that the detectable preclinical phase (sojourn time) was shorter than the screening interval.

Because interval breast cancers in some studies on average are larger, ${ }^{12}$ of a more advanced stage, ${ }^{1}$ and express proliferative markers more than screen detected tumours, ${ }^{13}$ it has been suggested that prognosis of interval breast cancers is poorer than that of screen detected breast cancers. ${ }^{3}$ However, prognostic studies may be misleading when comparing interval breast cancers with screen detected breast cancers because the screen detected breast cancers are affected by length bias sampling, lead time bias, and overdiagnosis bias. Therefore the valid comparison group for assessment of prognosis in women with interval breast cancers is non-screen detected cancers among women not invited to mammography screening, which are unaffected by the biases that screening entails. Comparisons with historical groups, as in many previous studies, may also lead to confounding because survival from breast cancer has improved over time..$^{45}$ Only a few, small studies have compared the survival of women with interval breast cancer with those with non-screen detected breast cancer, with inconsistent findings. ${ }^{6-13}$

In this population based study we took advantage of the nationwide breast cancer screening programme in Norway, which has been gradually implemented over a nine year period. ${ }^{13}$ This staggered roll out allowed a comparison between women with interval breast cancer and those with breast cancer 
diagnosed within the same period but before they had been invited to mammography screening.

We investigated whether breast cancers detected in the interval after a normal mammography screening result but before the next scheduled screening are more lethal and thus may need more aggressive treatment than non-screen detected breast cancers.

\section{Methods}

\section{Breast cancer screening programme}

Since 1951, reporting of cancer diagnoses to the nationwide Cancer Registry of Norway has been compulsory by national legislation. Patients are identified in the registry by their unique national registration number, assigned to all residents in Norway and including date of birth. The cancer registry has maintained nearly $100 \%$ completeness for solid cancers, including breast cancer. ${ }^{14} 15$

In 1996 the Norwegian breast cancer screening programme started in four counties and then expanded gradually, county by county, over the course of nine years. ${ }^{413}$ Since 2005 , all women in Norway aged 50-69 years are invited to mammography screening every two years. The Central Population Register of Norway identifies women eligible for screening by their national registration number. Invitations are posted to each eligible woman, suggesting an appointment time. ${ }^{16}$ Two radiologists independently read two view mammograms (craniocaudal views and mediolateral oblique views) in accordance with European guidelines for quality assurance, ${ }^{17}$ which are classified according to a five point interpretation scale reflecting the probability of cancer. ${ }^{18}$ The decision as to whether further diagnostic examinations are necessary is based on the consensus of two experienced radiologists. After this final decision, no further diagnostic tests are done before the next scheduled screening invitation.

For the purpose of the study we classified women as having interval cancer if breast cancer was diagnosed within two years and two months of the last normal screening mammogram but before invitation to the next screening. Hence the cohort of women with interval cancers included only those who were invited participants in the screening programme but had non-screened detected breast cancer. For the present analysis we extended the screening interval by two months because we retrieved date of diagnosis from two databases that were not completely in agreement about the date; the additional two months made it possible to include all women classified as having interval cancers in the screening database. Among women who reach the upper age limit of 70 years for invitation to screening, we defined interval cancers as those diagnosed within two years and two months after the last normal screening examination.

We further divided the cancers into groups (six month intervals) according to the time between the date of diagnosis and the date of the last normal screening examination, to explore the hypothesis that more rapidly growing cancers arising shortly after a normal screening mammogram have a poorer prognosis. ${ }^{81920}$ Owing to increased experience by the radiologists, screening sensitivity might increase with increasing screening rounds. Under this assumption the number of cancers overlooked at screening mammography should decline with time since start of the screening programme. Thus a growing proportion of cancers detected between scheduled screenings should be true interval cancers. If true interval cancers were a more aggressive subtype of breast cancers, in theory the survival of women with these tumours might be worse than for those whose breast cancer is overlooked, and with increasing screening rounds and more experience the prognosis would be worse. We therefore carried out a secondary analysis restricted to interval breast cancers stratified by screening round.

\section{Study population}

From the cancer registry database we retrieved information on date of diagnosis, age at diagnosis, county of residency, classification of the cancer according to the pathological tumour, node, metastases (pTNM) classification (International Union Against Cancer guidelines) ${ }^{21}$ and tumour stage in all women with a first diagnosis of invasive breast cancer at age 50 to 72 years in Norway between 1 January 1996 and 31 December 2006. The stage of breast tumour is coded as I (localised cancer), II (regional cancer), III (cancer fixed to the skin or the chest wall), or IV (cancer with distant metastases). To determine whether a diagnosis was made before or after invitation to screening we linked data on all the women to the screening database at the cancer registry. We then further categorised women with breast cancer diagnosed after invitations to screening as interval cancers if they met our criteria.

From the screening database we further retrieved data on tumour grade (based on the Nottingham grading system, I-III ${ }^{22}$ ); oestrogen and progesterone receptor status ${ }^{21}$; pTNM classification; and dates of invitation and attendance to the screening programme. We classified oestrogen and progesterone receptors as positive ( $\geq 10 \%$ positive staining) or negative $(<10 \%$ positive staining). These data were not available from the registry's database and as a result are not available for women not invited to mammography screening. We defined screening rounds by county rather than by individual women. The follow-up period was from 1 January 1996 to 31 December 2006. Linkage to the Central Population Register of Norway and the National Death Register allowed censoring at date of emigration or death. For the purpose of this study we defined two study cohorts:

- Interval cancer group - comprising all women with a first diagnosis of invasive breast cancer during the interval between two screening rounds or breast cancer diagnosed within two years and two months after the date of the last normal examination in the breast cancer screening programme between 1996 and 2006.

- Non-screened cancer group - comprising all women with a first diagnosis of invasive breast cancer who had not yet been invited to the breast cancer screening programme between 1996 and 2006.

\section{Statistical analyses}

We used the Pearson $\chi^{2}$ test to compare the interval cancer group with the non-screened cancer group according to the characteristics of the tumours, and we used a linear regression model to test trends across time intervals from a last normal screening result. Using life table techniques we calculated breast cancer specific survival rates and overall survival rates, illustrated by Kaplan-Meier plots, and we compared these rates using the log rank test. Censoring occurred at date of emigration, date of death from causes other than breast cancer, or the end of the follow-up period (31 December 2006), whichever came first.

Hazard ratios were calculated using Cox proportional hazard models. We used likelihood ratio statistics to compare groups. We adjusted for age at diagnosis by four categories: $50-54$, 55-59, 60-64, and 65-72 years. We further adjusted for time 
trends, county of residence, and time since last normal screening result. Because survival from breast cancer differed between counties, we adjusted for county and time trends by including county specific trend variables in the model. ${ }^{4} \mathrm{We}$ did not adjust for stage at diagnosis owing to the likelihood of stage migration, ${ }^{23}$ but we carried out further analyses stratified by stage. For interval cancers only, we carried out secondary analyses to examine the association and possible interaction of time since last normal screening result and screening round. The proportional hazards assumption was tested by both graphical methods and Schoenfeld residuals and it was achieved.

All test statistics were two tailed, and we considered $\mathrm{P}$ values $<0.05$ to be significant. Calculations were done with the statistical package Stata 10.0.

\section{Results}

Table $1 \Downarrow$ summarises the characteristics of the 1816 women in the interval cancer group and the 5300 women in the non-screened cancer group. The mean age at diagnosis was similar between the groups, whereas the mean follow-up time was 3.6 (SD 2.6, maximum 10.6) years for the interval cancer group and 6.3 (SD 3.0, maximum 11.2) years for the non-screened cancer group. Compared with the non-screened cancer group, the interval cancer group had a slightly higher proportion of lobular cancers, large tumours ( $>20 \mathrm{~mm}$ diameter), negative axillary lymph nodes, and stage II rather than stage I disease (table 1). The proportion of women who had a sentinel node biopsy was about three times higher in the interval cancer group than in the non-screened cancer group. Adjuvant tamoxifen was given to 701 (38.6\%) of the women in the interval cancer group and 1912 (36.1\%) in the non-screened cancer group.

Table $2 \Downarrow$ shows the characteristics of interval breast cancers by six month intervals from date of the last normal screening result. The number of interval cancers increased with increasing time after a normal result. The mean tumour diameter for interval cancers increased by only $2.2 \mathrm{~mm}$ during the two years after a normal screening result ( $\mathrm{P}$ for trend 0.03 ). There was no evidence that any other tumour characteristics varied by time since last normal screening result. The results were essentially the same with shorter intervals (data not shown).

Cumulative breast cancer survival did not differ between the two groups $(\mathrm{P}=0.53$, fig $1 \Downarrow)$. After 10 years of follow-up, the survival rate among women with interval cancers was $79.1 \%$ (95\% confidence interval $75.4 \%$ to $82.3 \%$ ) and among women with cancers in the non-screened group was $76.8 \%$ (75.3\% to $78.2 \%)$. Five year and 10 year age adjusted survival estimates by tumour stage at diagnosis were also similar for the study groups (data not shown). Cumulative overall survival did not differ between the two groups ( $\mathrm{P}=0.67$, fig $2 \Downarrow)$. After 10 years of follow-up, the overall survival rate among women with interval cancers was $72.6 \%$ (68.5\% to $76.3 \%)$ and among women with cancers in the non-screened group was $68.9 \%$ (67.3\% to $70.5 \%)$

Table $3 \Downarrow$ shows data derived from Cox proportional hazards model analyses of age at diagnosis and time since last normal screening result as possible determinants of a difference in survival between the cancer groups. Breast cancer specific mortality did not differ between the interval cancer group and the non-screened cancer group (hazard ratio $0.98,95 \%$ confidence interval 0.84 to $1.15, \mathrm{P}=0.81$ ). There was no association between time since last normal screening result and survival (table 3 ). The results did not change after adjustment for age at diagnosis, year of diagnosis, and county of residency (data not shown).

A secondary analysis restricted to interval cancers and stratified by screening round showed no evidence that survival was associated with screening round, either overall or after stratification by time since last normal screening result (table $4 \Downarrow$ ). Furthermore, after up to four screening rounds, the incidence of interval cancers was not associated with number of screening rounds. When the analysis was restricted to counties with a minimum of two years and two months of follow-up after examination, the incidence per 100000 woman years was 163.4 in the first screening round, 162.5 in the second, 193.3 in the third, and 166.5 in the fourth.

\section{Discussion}

The survival of women with a diagnosis of interval breast cancer after a normal mammogram is similar to that of women with breast cancer diagnosed before an invitation to a breast cancer screening programme. Contrary to our a priori hypothesis, we found no evidence that tumours that become clinically evident shortly after the last normal screening result were more aggressive in terms of larger size, higher grade, higher proportion of node metastases, or lower survival than non-screen detected breast cancers. Among the interval cancers, average tumour size increased slightly over time since last normal screening result, but no other characteristics of the tumour or risk of dying from breast cancer varied by time since the last normal screening result.

Although several investigators have examined whether interval cancers are associated with poor survival, controversy remains. Previous studies have been limited by small sample size sil $^{7024-27}$; invalid comparison groups, notably screen detected cancers ${ }^{92-27}$; or use of historical controls. ${ }^{811}{ }^{12}$ Furthermore, the findings in these studies were inconsistent. Analysis based on randomised trials of mammography screening found that survival with interval cancers was similar, ${ }^{72}$ better ${ }^{20}$ or poore ${ }^{24}$ than survival with non-screen detected cancers. Although studies based on randomised trials have a valid comparison group, chance could explain the inconsistent findings because the sample sizes in all the studies were limited ( $<100$ interval cancers). ${ }^{702428}$

In observational studies, where survival rates of women with interval cancers are compared with those of women with screen detected cancers or historical controls, or both, survival associated with interval cancers was similar to that of non-screen detected cancers in some studies,,${ }^{911}{ }^{126}$ worse in others, ${ }^{14}$ and worse than screen detected cancers but better than clinically detected cancers in studies where interval cancers were compared with both screen detected and historical controls. ${ }^{1012} 14{ }^{20}$ However, in these studies comparisons are likely to be confounded by lead time, overdiagnosis, and temporal trends in survival from breast cancer. ${ }^{4511}$ The only remaining alternative is contemporary patients unaffected by mammography screening. Theoretically, the ideal comparison group would be breast cancer diagnosed among unscreened women who would have attended screening if they had been invited. Such a design would eliminate the potential confounding by factors that affect both attendance and outcome. However such a study is not feasible; to our knowledge there is limited reason in the Norwegian healthcare system to believe in any substantial bias through this mechanism, and this bias, if it exists, would affect only a small proportion of incident breast cancers because the attendance rate in the Norwegian mammography screening programme is high (77\% among invited women). Overall survival was similar between women 
with interval cancers and those with non-screen detected cancers (fig 2), indicating that the results were not influenced by the potential selection bias among women with interval cancer.

\section{Strengths and limitations of this study}

To date, this population based study is the largest in the area of interval breast cancer and has the longest follow-up. The staggered introduction of the screening programme and the comparison of interval cancers with non-screen detected breast cancer avoided major biases.

This study, however, has several potential limitations. Because only a few of the interval cancers had been individually reviewed, we were unable to distinguish true interval cancers from those overlooked when the mammograms were examined. In a previous review in Norway comprising around 200 interval cancers, $35 \%$ were reinterpreted as overlooked, $23 \%$ showed minimal signs of malignancy, and $42 \%$ were true interval cancers, ${ }^{29}{ }^{30}$ similar to the results of other studies. ${ }^{31}{ }^{32}$ The overlooked tumours were on average larger and more often node positive than the true interval cancers. This could be because the affected women were reassured by the last normal mammogram result and therefore delayed seeking medical care. However, other studies have found no differences in survival between interval cancers classified as true or overlooked. ${ }^{33}{ }^{34}$

In each Norwegian county, introduction of the breast cancer screening programme was preceded by the establishment of specialised multidisciplinary teams. ${ }^{413}$ The goal of these teams was to provide the best possible management of all women with newly diagnosed breast cancers in the county, regardless of whether the cancer was diagnosed by mammography screening. We have shown previously that this optimised management entailed a substantial reduction in mortality also among women with breast cancer not diagnosed by mammography screening. ${ }^{4} 13$ Owing to the design of our current study, only women with interval cancers were managed by multidisciplinary teams. Hence it is conceivable that better treatment eliminated altogether a poorer prognosis among the women with interval cancers than among those with non-screen detected cancers. The possible influence of such confounding could not be tested in our study because it would have required more detailed individual data on prognostic factors, treatment, and overall management. However, the similar proportion of women in each group who received adjuvant tamoxifen treatments provides some reassurance against a major confounding.

\section{Conclusions}

We conclude that tumours associated with interval breast cancers are more likely to be larger than those diagnosed in the absence of mammography screening; but they have strikingly similar survival outcomes. Furthermore, the characteristics of the tumours (except for an increase of $2.2 \mathrm{~mm}$ in diameter) and the prognosis of women with interval cancers were not associated with time since last mammography. These findings challenge the theory of a strong correlation between growth rate and metastatic behaviour. Our study provides no compelling support for more aggressive primary treatment of interval breast cancers than non-screen detected cancers with similar prognostic features. ${ }^{14}$

Contributors: MK designed the study and did the statistical analysis. MK had full access to the data in the study and takes responsibility for the integrity of the data and the accuracy of the data analysis. MK, RT, $\mathrm{MB}$, and $\mathrm{HOA}$ interpreted the data and cowrote and edited the paper.
Funding: This study was funded by research grants from the Norwegian Research Council and Frontier Science. The funders had no role in the design and conduct of the study; the collection, management, analysis, and interpretation of the data; and the preparation, review, or approval of the manuscript.

Competing interests: All authors have completed the ICMJE uniform disclosure form at www.icmje.org/coi_disclosure.pdf (available on request from the corresponding author) and declare: no support from any organisation for the submitted work; no financial relationships with any organisations that might have an interest in the submitted work in the previous three years; no other relationships or activities that could appear to have influenced the submitted work.

Ethical approval: The research protocol was approved by the Norwegian Social Science Data Services 2008. Individual informed consent was not requested.

Data sharing: No additional data available.

1 Collett K, Stefansson IM, Eide J, Braaten A, Wang H, Eide GE, et al. A basal epithelia phenotype is more frequent in interval breast cancers compared with screen detected tumors. Cancer Epidemiol BiomarkersPrev 2005;14:1108-12.

2 Gilliand FD, Joste N, Stauber PM, Hunt WC, Rosenberg R, Redlich G, et al. Biologic characteristics of interval and screen-detected breast cancers. J Natl Cancer Inst 2000;92:743-9.

3 Sihto H, Lundin J, Lehtimäki T. Molecular subtypes of breast cancer detected in mammography screening and outside of screening. Clin Cancer Res 2008;14:4103-10.

4 Kalager M, Haldorsen T, Bretthauer M, Hoff G, Thoresen SO, Adami HO. Improved breas cancer survival following introduction of an organized mammography screening program among both screened and unscreened women: a population-based cohort study. Breast Cancer Res 2009;1:R44.

5 Zackrisson S, Janzon L, Manjer J, Andersson I. Improved survival rate for women with interval breast cancer-results from the breast cancer screening programme in Malmö, Sweden 1976-1999. J Med Screen 2007;14:138-43.

6 Wang H, Bjurstam N, Bjørndal H, Braaten A, Eriksen L, Skaane P, et al. Interval cancers in the Norwegian breast cancer screening program: frequency, characteristics and use of HRT. Int J Cancer 2001;94:594-8.

7 Holmberg LH, Adami HO, Tabar L, Bergström R. Survival in breast cancer diagnosed between mammographic screening examinations. Lancet 1986;2:27-30.

8 Brekelmans CT, Peeters PH, Deurenberg JJ, Collette HJ. Survival in interval breast cance in the DOM screening programme. Eur J Cancer 1995;31:1830-5.

9 Schröen AA, Wobbes T, van der Sluis RF. Interval carcinomas of the breast: a group with intermediate outcome. J Surg Oncol 1996;63:141-4.

10 Collins S, Woodman CBJ, Threlfall A, Prior P. Survival rates from interval cancers in NHS breast screening programme. BMJ 1998;316:832-3

11 Bordás $\mathrm{P}$, Jonsson $\mathrm{H}$, Nyström L, Lenner $\mathrm{P}$. Survival from invasive breast cancer among interval cases in the mammography screening programmes of northern Sweden. Breast 2007; $16: 47-54$

12 Lawrence G, O'Sullivan E, Kearins O, Tappenden N, Martin K, Wallis M. Screening histories of invasive breast cancers diagnosed 1989-2006 in the West Midlands, UK: variation with time and impact on 10-year survival. J Med Screen 2009;16:186-92.

13 Kalager M, Zelen M, Langmark F, Adami HO. Effect of screening mammography on breast-cancer mortality in Norway. N Engl J Med 2010;363:1203-10.

14 Larsen IK, Småstuen M, Johannesen TB, Langmark F, Parkin DM, Bray F, et al. Data quality at the cancer Registry of Norway: an overview of comparability, completeness, validity and timeliness. Eur J Cancer 2009;45:1218-31.

15 Tingulstad S, Haldorsen T, Norstein J, Hagen B, Skjeldestad FE. Completeness and accuracy of registration of ovarian cancer in the cancer registry of Norway. Int $\mathrm{J}$ Cancer 2002;98:907-11.

16 Wang $\mathrm{H}$, Kåresen R, Hervik A, Thoresen S. Mammography screening in Norway: results from the first screening round in four counties and cost effectiveness of a modeled nationwide screening. Cancer Causes Control 2001;12:39-45.

17 Perry N, Broeders M, de Wolf C. European guidelines for quality assurance in breast cancer screening and diagnosis. 2nd edn. Office for official publications of the European Communities, 1996

18 Erzaas A. Quality assurance manual of the norwegian breast cancer screening program [Norwegian]. The Cancer Registry of Norway; 2003. www.kreftregisteret.no.

19 Cowan WK, Angus B, Gray JC, Lunt LG, Al-Tamimi SR. A study of interval breast cancer within the NHS breast screening programme. J Clin Pathol 2000;53:140-6.

20 Frisell J, von Rosen A, Wiege M, Nilsson B, Goldman S. Interval cancers and survival in a randomised breast cancer screening trial in Stockholm. Breast Cancer Res Treat 1992;24:11-6.

21 Edge SB, Byrd DR, Compton CC, Fritz AG, Greene FL, Trotti A, eds. AJCC cancer staging manual, 7 th edn. Springer-Verlag, 2010.

22 Galea MH, Blamey RW, Elston CE, Ellis IO. The Nottingham Prognostic Index in primary breast cancer. Breast Cancer Res Treat 1992;22:207-19.

23 Feinstein AR, Sosin DM, Wells CK. The Will Rogers phenomenon. Stage migration and new diagnostic techniques as a source of misleading statistics for survival in cancer. $N$ Engl J Med 1985;312:1604-8.

24 Andersson I, Aspgren K, Janzon L, Landberg T, Lindholm K, Linell F, et al. Mammographic screening and mortality from breast cancer: the Malmö mammographic trial. $B M J$ 1988;29:943-8.

25 Vitak B, Stål O, Månson JC, Thomas BA, Arnesson LG, Ekelund L, et al. Interval cancers and cancers in non-attenders in the Östergötland mammographic screening programme. Duration between screening and diagnosis, s-phase fraction and distant recurrence. Eur J Cancer 1997:33:1453-60.

26 Rayson D, Payne JI, Abdolell M, Barnes PJ, Maclntosh RF, Foley T, et al. Comparison of clinical-pathologic characteristics and outcomes of true interval and screen-detected 


\section{What is already known on this topic}

Previous randomised trials on mammography screening found that interval breast cancers were associated with similar, better, or poorer survival compared with non-screened breast cancers

These inconsistent findings can be explained by small sample sizes ( $<100$ interval cancers)

Observational studies suggested that interval cancers were associated with poor survival but were limited by small sample size and invalid comparison groups

\section{What this study adds}

Interval breast cancers were more likely to be larger than breast cancers diagnosed in the absence of mammography screening Survival outcomes between the two cancer groups were, however, strikingly similar

Our study provides no compelling support for more aggressive primary treatment of interval breast cancers than non-screening cancers with similar prognostic features

invasive breast cancer among participants of a Canadian breast screening program: a nested case-control study. Clin Breast Cancer 2011;11:27-32.

27 DeGroote R, Rush BF Jr, Milazzo J, Warden MJ, Rocko JM. Interval breast cancer: a more aggressive subset of breast neoplasias. Surgery 1983;94:543-7.

28 Shapiro S, Venet W, Strax P, Venet L, Roeser R. Ten-to fourteen-year effect of screening on breast cancer mortality. J Natl Cancer Inst 1982;69:349-55.

29 Hofvind S, Skaane P, Vitak B, Wang H, Thoresen S, Eriksen L, et al. Influence of review design on percentages of missed interval breast cancers: a retrospect study of interval cancers in a population-based screening program. Radiology 2005;237:437-43.

30 Hofvind S, Geller B, Skaane P. Mammographic features and histopathological findings of interval breast cancers. Acta Radiol 2008;49:975-81.

31 Vitak B. Interval cancers in the Ostergötland Mammographic Screening Program: radiological analysis. Eur Radiol 1998;8:639-46.

32 Domingo L, Sala M, Servitja S, Corominas JM, Ferrer F, Martínez J, et al. Phenotypic characterizations and risk factors for interval breast cancers in a population-based breast cancer screening program in Barcelona, Spain. Cancer Causes Control 2010;21:1155-64.

33 Vitak B, Olsen KE, Månson JC, Arnesson LG, Stål O. Tumor characteristics and survival in patients with invasive interval breast cancer classified according to mammographic findings at the latest screening: a comparison of true interval and missed interval cancers. Eur Radiol 1999;9:460-9.

34 Porter GJR, Evans AJ, Burrell AJ, Lee AHS, Ellis IO, Chakrabarti J. Interval breast cancers: prognostic features and survival by subtype and time since last screen. $J$ Med Screen 2006;13:115-22

Accepted: 1 November 2012

Cite this as: BMJ 2012;345:e7536

This is an open-access article distributed under the terms of the Creative Commons Attribution Non-commercial License, which permits use, distribution, and reproduction in any medium, provided the original work is properly cited, the use is non commercial and is otherwise in compliance with the license. See: http://creativecommons.org/licenses/by$\mathrm{nc} / 2.0 /$ and http://creativecommons.org/licenses/by-nc/2.0/legalcode. 


\section{Tables}

Table 1/ Characteristics of women with breast cancer in interval cancer group and in non-screened cancer group. Values are numbers (percentages) unless stated otherwise

\begin{tabular}{|c|c|c|c|}
\hline Characteristics & Interval cancer group $(n=1816)$ & Non-screened cancer group $(n=5300)$ & $P$ value \\
\hline Mean (SD) age at diagnosis (years) & $59.4(5.7)$ & $60.1(7.1)$ & \\
\hline \multicolumn{4}{|l|}{ Histological type: } \\
\hline Ductal & $1377(75.8)$ & $4176(78.8)$ & \multirow[t]{3}{*}{$<0.001$} \\
\hline Lobular & $245(13.5)$ & $531(10.0)$ & \\
\hline Other & $194(10.7)$ & $593(11.2)$ & \\
\hline \multicolumn{4}{|l|}{ Tumour size*: } \\
\hline $1(<20 \mathrm{~mm})$ & $962(56.1)$ & $2464(59.9)$ & \multirow[t]{5}{*}{$<0.001$} \\
\hline $2(>20-50 \mathrm{~mm})$ & $574(33.5)$ & $1344(32.7)$ & \\
\hline $3(>50 \mathrm{~mm})$ & $137(8.0)$ & $106(2.6)$ & \\
\hline 4 (ingrowth) & $42(2.5)$ & $197(4.8)$ & \\
\hline Unknown & $101(5.6) \dagger$ & $1189(22.4) \dagger$ & \\
\hline \multicolumn{4}{|l|}{ Nodal status*: } \\
\hline Positive & $910(54.4)$ & $2805(58.7)$ & \multirow[t]{3}{*}{$<0.001$} \\
\hline Negative & $764(45.6)$ & $2491(41.3)$ & \\
\hline Missing & $142(7.8) \dagger$ & $520(9.8) \dagger$ & \\
\hline \multicolumn{4}{|l|}{ Stageł: } \\
\hline I & $750(41.5)$ & 2607 (49.4) & \multirow[t]{4}{*}{$<0.001$} \\
\hline II & $913(50.6)$ & $2236(42.4)$ & \\
\hline III & $56(3.1)$ & $153(2.9)$ & \\
\hline IV & $87(4.8)$ & $279(5.3)$ & \\
\hline Sentinel node biopsy & $869(47.9)$ & $798(15.0)$ & $<0.001$ \\
\hline Tamoxifen administered & $701(38.6)$ & $1912(36.1)$ & $<0.001$ \\
\hline Total No of deaths & $246(13.5)$ & $1307(24.7)$ & $<0.001$ \\
\hline Deaths from breast cancer & $194(10.7)$ & $979(18.5)$ & $<0.001$ \\
\hline
\end{tabular}

${ }^{*}$ Based on pathological tumour, node, and metastasis classification. ${ }^{21}$

$\dagger \%$ of total breast cancers.

łl, localised breast cancer; II, lymph node positive; III, growth into skin or chest wall; and IV, metastasis. Missing information on stage: 10 interval cancers and 25 non-screened cancers. 
Table 2| Tumour characteristics of interval breast cancers in six month intervals from last normal screening result to diagnoses. Values are numbers (percentages) unless stated otherwise

\begin{tabular}{|c|c|c|c|c|}
\hline \multirow[b]{2}{*}{ Characteristics } & \multicolumn{4}{|c|}{ Time since last normal screening result (months) } \\
\hline & $0-6(n=181)$ & $7-12(n=497)$ & $13-18(n=554)$ & $19-24(n=584)$ \\
\hline Mean (SD) tumour size (mm) & $19.3(12.2)$ & $19.8(11.8)$ & $20.6(12.5)$ & $21.5(13.4)$ \\
\hline Node negative & $86(52.1)$ & $253(54.5)$ & $267(52.8)$ & $304(56.4)$ \\
\hline Missing node status* & $16(8.8)$ & $33(6.6)$ & $48(8.7)$ & $45(7.7)$ \\
\hline Grade I & $35(24.0)$ & $81(19.6)$ & $92(20.2)$ & $130(27.0)$ \\
\hline Grade II & $67(45.9)$ & $206(49.9)$ & $214(46.9)$ & $213(44.3)$ \\
\hline Grade III & $44(30.1)$ & $126(30.5)$ & $150(32.9)$ & $138(28.7)$ \\
\hline Missing grade* & $35(19.3)$ & $84(16.9)$ & $98(17.7)$ & $103(17.6)$ \\
\hline \multicolumn{5}{|l|}{ Oestrogen receptor status: } \\
\hline Positive† & $92(74.8)$ & $224(69.6)$ & $251(71.7)$ & $245(73.8)$ \\
\hline Negativeł & $31(25.5)$ & $98(30.4)$ & $99(28.3)$ & $87(26.2)$ \\
\hline Missing data* & $58(32.0)$ & $175(35.2)$ & $204(36.8)$ & $252(43.2)$ \\
\hline \multicolumn{5}{|l|}{ Progesterone receptor status: } \\
\hline Positive† & $64(52.9)$ & $162(51.1)$ & $181(53.2)$ & $174(53.2)$ \\
\hline Negativeł & $57(47.1)$ & $155(48.9)$ & $159(46.8)$ & $153(46.8)$ \\
\hline Missing data* & $60(33.2)$ & $180(36.2)$ & $214(38.6)$ & $257(44.0)$ \\
\hline $\begin{array}{l}* \% \text { of total breast cancers. } \\
\dagger \geq 10 \% \text { positive staining. } \\
\ddagger<10 \% \text { positive staining. }\end{array}$ & & & & \\
\hline
\end{tabular}


Table 3| Hazard ratios (95\% confidence intervals) for breast cancer specific mortality between breast cancer groups overall and across age categories

\begin{tabular}{|c|c|c|c|c|c|c|c|c|c|c|}
\hline \multirow[b]{3}{*}{ Variables } & \multirow{2}{*}{\multicolumn{2}{|c|}{ Overall }} & \multicolumn{8}{|c|}{ Age at diagnosis (years) } \\
\hline & & & \multicolumn{2}{|l|}{$50-54$} & \multicolumn{2}{|l|}{$55-59$} & \multicolumn{2}{|l|}{$60-64$} & \multicolumn{2}{|l|}{$65-72$} \\
\hline & $\begin{array}{l}\text { Hazard ratio* } \\
\qquad(95 \% \mathrm{Cl})\end{array}$ & $\begin{array}{c}P \\
\text { value }\end{array}$ & $\begin{array}{l}\text { Hazard ratio } \\
(95 \% \mathrm{Cl})\end{array}$ & $\begin{array}{c}P \\
\text { value }\end{array}$ & $\begin{array}{l}\text { Hazard ratio } \\
(95 \% \mathrm{Cl})\end{array}$ & $\begin{array}{c}P \\
\text { value }\end{array}$ & $\begin{array}{l}\text { Hazard ratio } \\
\qquad(95 \% \mathrm{Cl})\end{array}$ & $\begin{array}{c}P \\
\text { value }\end{array}$ & $\begin{array}{l}\text { Hazard ratio } \\
(95 \% \mathrm{Cl})\end{array}$ & $\begin{array}{c}\mathbf{P} \\
\text { value }\end{array}$ \\
\hline \multirow{2}{*}{$\begin{array}{l}\text { Non-screened } \\
\text { cancer group }\end{array}$} & 1 (reference) & & 1 (reference) & & 1 (reference) & & 1 (reference) & & 1 (reference) & - \\
\hline & $\begin{array}{l}(\mathrm{n}=5300 \\
\text { cancers })\end{array}$ & & $\begin{array}{l}(\mathrm{n}=1507 \\
\text { cancers) }\end{array}$ & & $\begin{array}{l}\text { ( } \mathrm{n}=1558 \\
\text { cancers) }\end{array}$ & & ( $\mathrm{n}=963$ cancers $)$ & & $\begin{array}{l}\text { ( } \mathrm{n}=1672 \\
\text { cancers) }\end{array}$ & \\
\hline \multirow[t]{2}{*}{$\begin{array}{l}\text { Interval } \\
\text { cancer† group }\end{array}$} & $\begin{array}{c}0.98(0.84 \text { to } \\
1.15)\end{array}$ & 0.81 & $\begin{array}{c}0.81(0.57 \text { to } \\
1.16)\end{array}$ & 0.25 & $\begin{array}{c}1.13(0.86 \text { to } \\
1.49)\end{array}$ & 0.37 & $\begin{array}{c}0.89(0.61 \text { to } \\
1.30)\end{array}$ & 0.55 & $\begin{array}{c}1.02(0.76 \text { to } \\
1.37)\end{array}$ & 0.89 \\
\hline & $\begin{array}{l}(n=1816 \\
\text { cancers) }\end{array}$ & & ( $n=429$ cancers $)$ & & ( $\mathrm{n}=578$ cancers $)$ & & ( $\mathrm{n}=399$ cancers $)$ & & ( $\mathrm{n}=410$ cancers $)$ & \\
\hline \multicolumn{11}{|l|}{$\begin{array}{l}\text { Months since } \\
\text { last screen: }\end{array}$} \\
\hline $0-6$ & $\begin{array}{c}1.09(0.70 \text { to } \\
1.67)\end{array}$ & \multirow[t]{4}{*}{$0.53 \ddagger$} & $\begin{array}{c}0.68(0.28 \text { to } \\
1.65)\end{array}$ & \multirow[t]{4}{*}{$0.61 \neq$} & $\begin{array}{c}1.61(0.80 \text { to } \\
3.29)\end{array}$ & \multirow[t]{4}{*}{$0.84 \ddagger$} & $\begin{array}{c}1.19(0.44 \text { to } \\
3.21)\end{array}$ & \multirow[t]{4}{*}{$0.78 \ddagger$} & $\begin{array}{c}1.12(0.42 \text { to } \\
3.00)\end{array}$ & \multirow[t]{4}{*}{$0.91 \ddagger$} \\
\hline $7-12$ & $\begin{array}{c}0.97(0.74 \text { to } \\
1.28)\end{array}$ & & $\begin{array}{c}0.81 \text { (0.43 to } \\
1.53)\end{array}$ & & $\begin{array}{c}1.19(0.77 \text { to } \\
1.85)\end{array}$ & & $\begin{array}{c}0.82(0.42 \text { to } \\
1.60)\end{array}$ & & $\begin{array}{c}0.97(0.56 \text { to } \\
1.69)\end{array}$ & \\
\hline $13-18$ & $\begin{array}{c}1.06(0.82 \text { to } \\
1.36)\end{array}$ & & $\begin{array}{c}1.00(0.58 \text { to } \\
1.76)\end{array}$ & & $\begin{array}{c}1.04(0.67 \text { to } \\
1.64)\end{array}$ & & $\begin{array}{c}1.37(0.72 \text { to } \\
2.09)\end{array}$ & & $\begin{array}{c}1.01(0.62 \text { to } \\
1.68)\end{array}$ & \\
\hline $19-26$ & $\begin{array}{c}0.87 \text { (0.66 to } \\
1.15)\end{array}$ & & $\begin{array}{c}0.66(0.31 \text { to } \\
1.40)\end{array}$ & & $\begin{array}{c}1.04(0.66 \text { to } \\
1.65)\end{array}$ & & $\begin{array}{c}0.52(0.23 \text { to } \\
1.19)\end{array}$ & & $\begin{array}{c}1.04 \text { (0.66 to } \\
1.63)\end{array}$ & \\
\hline
\end{tabular}

*Age adjusted.

†Categorised as time since last normal mammogram (time since last screen) in six month intervals.

$\ddagger \mathrm{P}$ for trend. 
Table 4| Age adjusted hazard ratios (95\% confidence intervals) for breast cancer specific mortality among women with interval breast cancers comparing screening round according to time since last normal screening result

\begin{tabular}{|c|c|c|c|c|c|c|}
\hline \multirow[b]{2}{*}{ Screening round (No of cancers) } & \multirow[b]{2}{*}{ Overall } & \multicolumn{4}{|c|}{ Time since last normal screening result (months) } & \multirow[b]{2}{*}{ P for trend } \\
\hline & & $0-6$ & 7-12 & 13-18 & $19-24$ & \\
\hline $1(n=564)$ & 1 (reference) & 1 (reference) & 1 (reference) & 1 (reference) & 1 (reference) & 0.41 \\
\hline $2(n=475)$ & 0.89 (0.63 to 1.27$)$ & $0.85(0.28$ to $2 \cdot 64)$ & $1.06(0.55$ to 2.06$)$ & 0.55 (0.29 to 1.02$)$ & $1.48(0.76$ to 2.87$)$ & 0.72 \\
\hline $3(n=355)$ & $0.86(0.58$ to 1.27$)$ & $1.07(0.36$ to 3.23$)$ & $1.18(0.58$ to 2.41$)$ & $0.39(0.17$ to 0.89$)$ & $1.18(0.54$ to 2.60$)$ & 0.85 \\
\hline $4(n=220)$ & $0.69(0.39$ to 1.21$)$ & $0.32(0.04$ to $2 \cdot 61)$ & $0.66(0.22$ to 1.94$)$ & $0.43(0.15$ to 1.23$)$ & 1.65 (0.64 to 4.29$)$ & 0.74 \\
\hline $5(n=182)$ & $0.99(0.42$ to 2.31$)$ & $1.19(0.37$ to $9 \cdot 88)$ & $0.38(0.05$ to 2.93$)$ & $1.39(0.40$ to 4.80$)$ & - & 0.17 \\
\hline
\end{tabular}




\section{Figures}

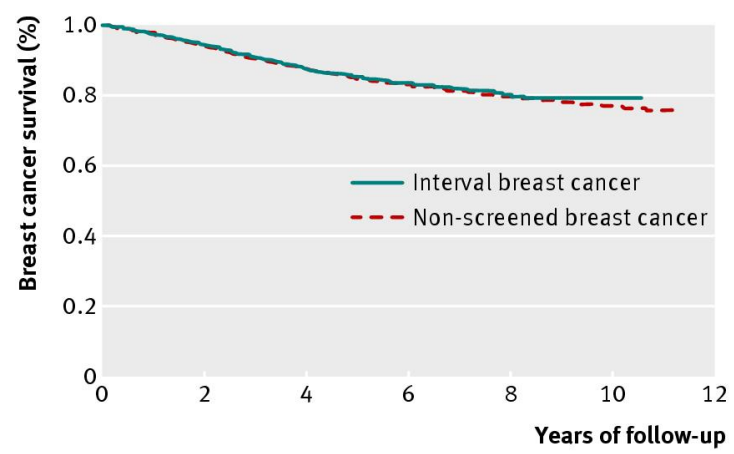

Fig 1 Cumulative breast cancer survival plot for women with breast cancer by group

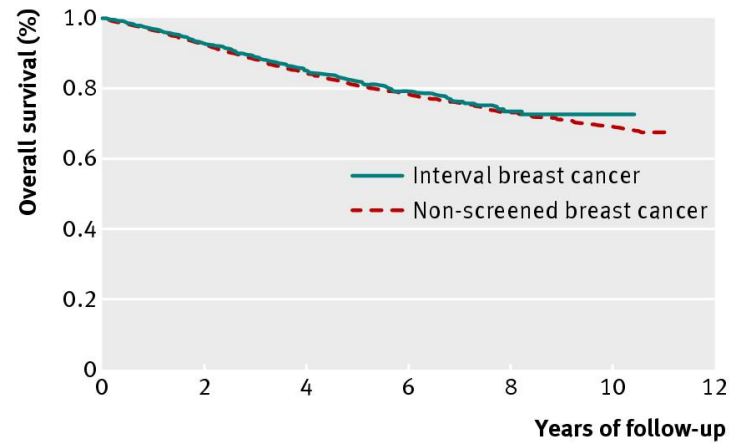

Fig 2 Cumulative overall survival plot for women with breast cancer by group 